\title{
Fish hosts of the freshwater mussel Unio foucauldianus Pallary, 1936
}

\author{
Hassan Benaissa ${ }^{1}$ (D) | Amílcar Teixeira ${ }^{2}$ | Manuel Lopes-Lima ${ }^{3,4}$ (D) | Ronaldo Sousa ${ }^{4,5}$ (D) । \\ Simone Varandas ${ }^{6}$ | Hanane Rassam ${ }^{1}$ | Mohamed Ghamizi ${ }^{1}$
}

\author{
${ }^{1}$ Department of Biology, Natural History \\ Museum of Marrakech, University of Cadi \\ Ayyad, Marrakech, Morocco \\ ${ }^{2}$ CIMO/ESA-IPB - Mountain Research Centre, \\ School of Agriculture, Polytechnic Institute of \\ Bragança, Bragança, Portugal \\ ${ }^{3} \mathrm{CIBIO} / \mathrm{InBIO}$ - Research Centre in \\ Biodiversity and Genetic Resources, \\ Universidade do Porto, Vairão, Portugal \\ ${ }^{4}$ CIIMAR/CIMAR - Interdisciplinary Centre of \\ Marine and Environmental Research, \\ University of Porto, Matosinhos, Portugal \\ ${ }^{5}$ CBMA - Centre of Molecular and \\ Environmental Biology, Department of \\ Biology, University of Minho, Braga, Portugal \\ ${ }^{6}$ CITAB/UTAD - Centre for Research and \\ Technology of Agro-Environment and \\ Biological Sciences, University of Trás-os- \\ Montes and Alto Douro, Vila Real, Portugal

\section{Correspondence} \\ Hassan Benaissa, Department of Biology, \\ Natural History Museum of Marrakech, \\ University of Cadi Ayyad, B.P. 2390, \\ Marrakech, Morocco \\ Email: benaissahassan2@gmail.com \\ Funding information \\ IUCN SOS Save our Species fund, Grant/ \\ Award Number: 2015B-015; Mohamed Bin \\ Zayed Species Conservation Fund, Grant/ \\ Award Number: 15256799
}

\section{Abstract}

1. The life cycle of Unio foucauldianus Pallary, 1936, a critically endangered freshwater mussel species (Bivalvia: Unionida), includes a parasitic phase using fish as hosts. Therefore, to develop more efficient conservation strategies it is essential to know which are the suitable fish hosts of $U$. foucauldianus.

2. In this study, two approaches were used to assess the fish hosts of $U$. foucauldianus: the determination of infestation rates of fishes under natural conditions through monthly sampling (from January to June) in the Laabid River (Oum Rbia basin) and the N'Fis River (Tensift basin), and artificial infestation in laboratory trials using fish species from both rivers.

3. The natural infestation of fish was detected from February to June, with a peak in May. Fully metamorphosed juveniles were only detected in native fish species, i.e. Luciobarbus ksibi (Boulenger, 1905), Carasobarbus fritschii (Günther, 1874), Luciobarbus zayanensis Doadrio, Casal-lopez \& Yahyaoui, 2016, Labeobarbus maroccanus (Günther, 1874), and Luciobarbus magniatlantis (Pellegrin, 1919). The two non-native fish species used do not function as effective hosts.

4. Given the increasing human pressure on native fish species in the Mediterranean biodiversity hotspot, including the increased number of non-native fish introductions, urgent conservation measures are discussed for this and other freshwater mussel species.

\section{KEYWORDS}

conservation, fish hosts, glochidia, infestation, Laabid River, Morocco, N'Fis River, non-native

\section{1 | INTRODUCTION}

Freshwater mussels (Bivalvia: Unionida) are among the most threatened animals globally (Lopes-Lima et al., 2014; Lopes-Lima et al., 2017; Lopes-Lima et al., 2018), and species present in Morocco such as Unio foucauldianus, Pallary, 1936 are no exception (Froufe et al., 2016; Van Damme \& Ghamizi, 2010). Although highly threatened, the limited studies on freshwater mussels in Africa are mainly focused on resolving taxonomic problems (Froufe et al., 2016). Even fewer are studies focusing on the ecology and conservation of these species (but see Sousa et al., 2016, Sousa et al., 2018), where basic biological data such as density, biomass, reproductive cycle, and fish hosts are lacking.

This absence of data for key autecological features impairs the application of management measures that could help freshwater mussel conservation. The life cycle of freshwater mussels requires a temporary but obligatory stage using mainly fish species (for a review, see Modesto 
et al., 2018). Females brood the fertilized eggs in their marsupial demibranches, and after the embryonic phase release larvae (glochidia) using different strategies (Haag, 2012). The glochidia need to attach to a suitable fish host and then metamorphose into free-living juveniles (Arey, 1921; Coker, Shira, Clark, \& Howard, 1921; Reis, Collares-Pereira, $\&$ Araujo, 2014). This relationship is thought to be primarily phoretic rather than nutritive (Watters, 2001), and a growing number of studies show evidence that this relationship may be parasitic (Denic, Taeubert, \& Geist, 2015; Fritts, Fritts, Carleton, \& Bringolf, 2013).

For the Unio genus, different studies have shown the diversity of suitable fish hosts (Ćmiel, Zając, Lipińska, \& Zając, 2018; Douda, Horký, \& Bílý, 2012; Lamand, Roche, \& Beisel, 2016; Nagel \& Castagnolo, 1991; Reis et al., 2014; Schneider, Nilsson, Höjesjö, \& Österling, 2017; Taeubert, Gum, \& Geist, 2012; Taeubert, Martinez, Gum, \& Geist, 2012). Unio foucauldianus is an endemic species of Moroccan rivers (Froufe et al., 2016), being listed as Critically Endangered by the International Union for Conservation of Nature (IUCN) (Van Damme \& Ghamizi, 2010). This species usually occurs in the permanent areas of the middle and lower sections of rivers and streams in a great variety of substrates, from silt to sand and gravel, and is generally found close to the banks (authors' pers. obs.). Its distribution covers most of the major basins of Morocco, from the Noun, on the South Atlantic coast, to the Moulouya, on the north-east Mediterranean coast. The species has been declining significantly, however, mainly in the southern part of the country where many populations have been extirpated in response to more frequent and intense droughts and water abstraction, brought about by increased agricultural, industrial, and domestic demand (Gomes-dos-Santos et al., 2019). Nevertheless, and despite some recent data on the taxonomy, genetics, and distribution of $U$. foucauldianus, great ignorance remains about most of their autoecology, including the reproductive cycle and the identification of the most suitable fish hosts.

Given the conservation importance of $U$. foucauldianus and the urgency to collect basic information on key autecological features, this study is a very important first step towards a better understanding of the host-mussel relationship that could guide further research and application of management actions. The aim of this work was to determine the fish hosts using a dual approach: (i) monthly monitoring of the fish community in natural conditions to identify the ecological hosts of $U$. foucauldianus; and (ii) assessing effective $U$. foucauldianus fish hosts that are able to transform glochidia into juveniles successfully using manipulative infestations in the laboratory. Following earlier results using other unionid species (Douda et al., 2013; Modesto et al., 2018; Moore, Collier, \& Duggan, 2019), we hypothesize that native fish will be more infested and more effective as $U$. foucauldianus hosts than non-native fish species.

\section{2 | MATERIALS AND METHODS}

\section{1 | Study area}

The present study was conducted in the rivers Laabid and N'Fis (Figure 1). The Laabid River with an approximate length of $200 \mathrm{~km}$ originates in the Atlas Mountains and drains to the Oum Er Rbia River. The Laabid basin is located between the High Atlas and the plain of Tadla, and this river is considered one of the most important water resources of Morocco, being used for irrigation and hydropower generation. The annual average rainfall in the Laabid River between 2017 and 2018 was 271 mm (ABHOER, 2017). The N'Fis River, which is located in the High Atlas, belongs to the Tensift basin. The N'Fis River has a total length of $152 \mathrm{~km}$ and drains into the Lalla Takerkoust dam. The area is characterized by a semi-arid climate, with an average annual rainfall of $\sim 259 \mathrm{~mm}$ in Lalla Takerkoust dam (Amaya, Algouti, \& Algouti, 2014; JICA, 2007). Populations of U. foucauldianus have been found only in the lower parts of the two rivers and usually near the river banks. Both rivers are characterized by permanent flow and a habitat consisting of cobbles, gravel, and sands, and in some parts muddy sediments.

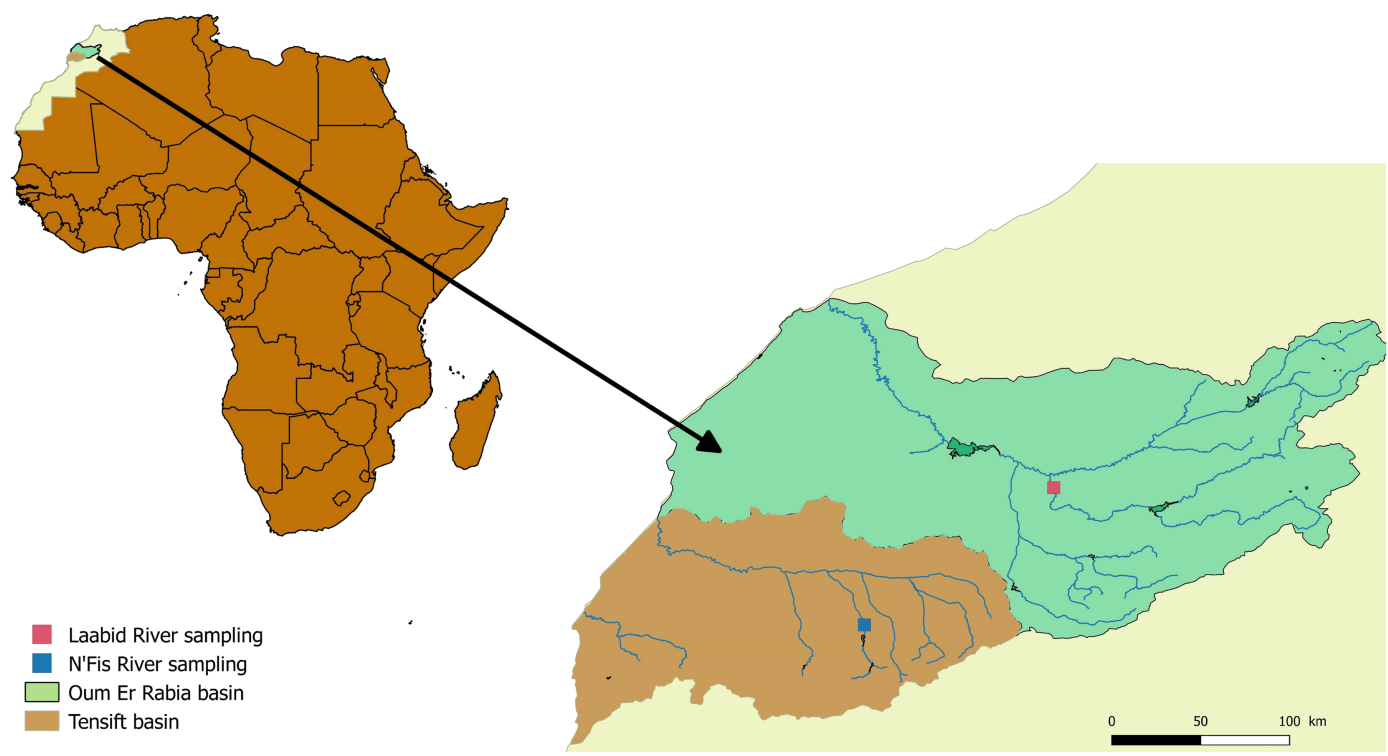

FIGURE 1 Map of the study area and the location of the two sampling sites 


\subsection{Field sampling and laboratory infestation}

Monitoring the presence of $U$. foucauldianus glochidia was carried out monthly at two sites located in the Laabid and N'Fis rivers between January and June 2017. At each site, a 100-m river section was surveyed for $20 \mathrm{~min}$ (covering all different habitats, e.g. riffles, pools, banks, and the centre of the river channel) using electrofishing to capture the potential fish hosts. In addition, the density and relative abundance of fish were also determined. For $U$. foucauldianus, the abundance per site was recorded as the total number of individuals found in 15 min per person (two replicates for each site, totalling $30 \mathrm{~min}$ of survey time per site). Abundance is represented here by the number of individuals as catch per unit effort (ind. CPUE).

All fish were visually inspected on site for glochidia infestation (using a mobile phone with a magnification application). Infested fish (117 and 47 from the N'Fis and Laabid rivers, respectively) from the two rivers were brought to the laboratory in a refrigerated tank for confirmation and evaluation of the glochidial load. All encysted glochidia were counted for each fish in order to calculate the number of glochidia per individual of a given species per month (using loupe magnification; $\mathrm{CH}$ 9435; Leica Microsystems, Wetzlar, Germany). Encysted glochidia were then pumped by pipette and placed in tubes containing 95\% ethanol. Each tube was tagged with site identification, fish taxonomy, and date, and deposited at the Natural History Museum of Marrakech.
For the laboratory experiments, gravid females (verified in the field by carefully opening the shells and observing the swelling of gills) were collected by snorkelling at each site (15 individuals per site) and transported to the laboratory in a refrigerated tank. The target fish species for the infestation experiments were selected based on their coexistence with $U$. foucauldianus at each study site (Figure 2). All fish were collected at the same sites in the Laabid and N'Fis rivers. Smaller fish were chosen to reduce any potential biases arising from acquired immunity after previous exposure to glochidia. The fish were collected by electro-fishing using a similar approach as described above and transported live (139 individuals) to the laboratory in a refrigerated tank $\left(21^{\circ} \mathrm{C}\right)$ with stream water. To determine the transformation of $U$. foucauldianus glochidia into juveniles, an artificial infestation was performed in the laboratory. For this, the gravid mussels and fish hosts collected at both sites were maintained at the Museum of Natural History of Marrakech in aerated aquaria, with an average temperature of $23^{\circ} \mathrm{C}$. Water exchanges and inspection for released glochidia were carried out daily. From the 15 mussels collected at each site for the laboratory experiments, eight were returned to the river and seven were deposited as voucher specimens at the Museum of Natural History of Marrakech.

The laboratory experiments were conducted from 10 May to 2 June 2017. Glochidia were extracted from the gills of gravid mussels $(n=15)$ through the exhalent apertures with a pipette. Glochidia and individual fish $(n=139)$ of all species collected (Carasobarbus fritschii, Gambusia
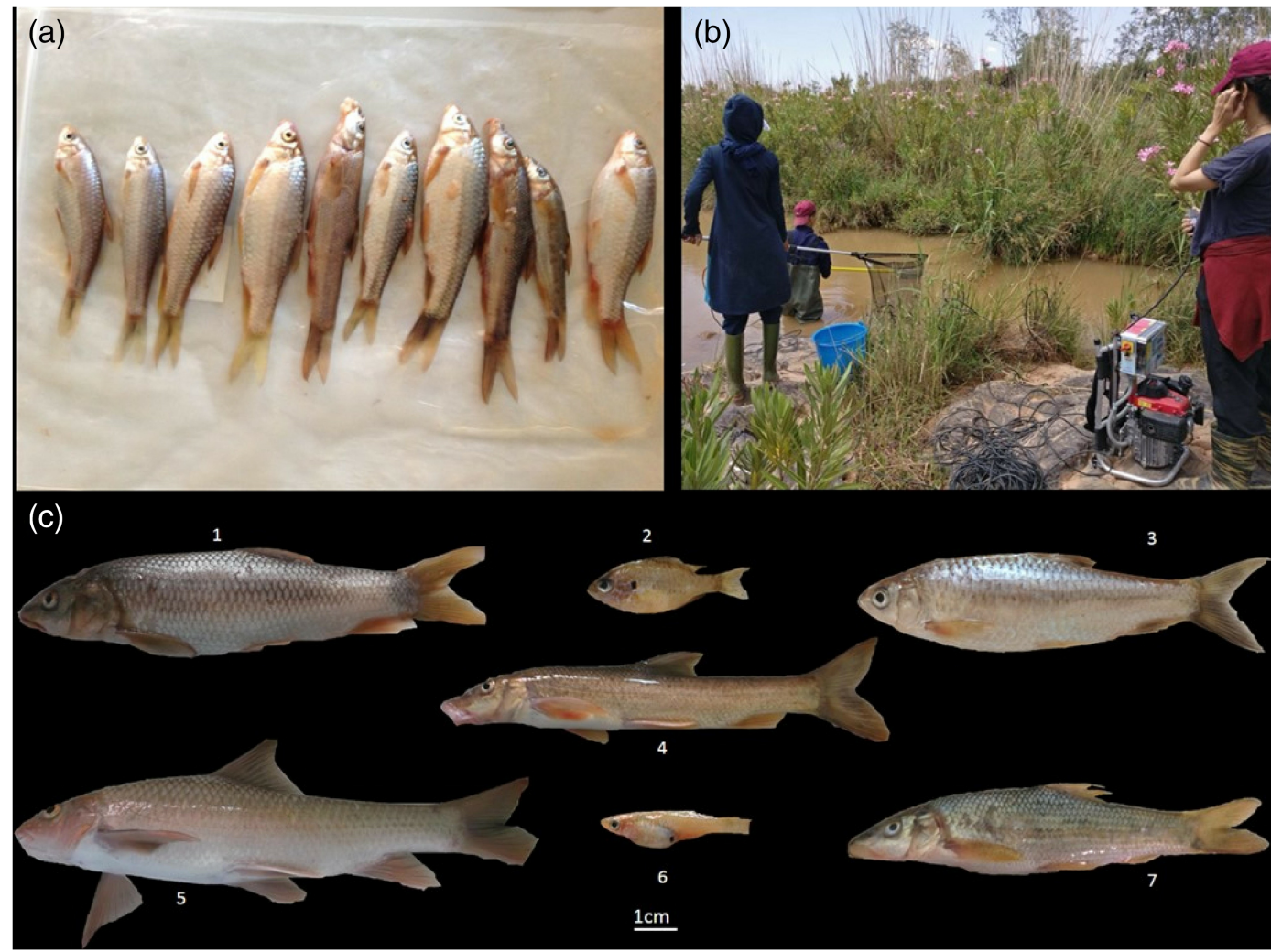

FIGURE 2 (a) Natural infestation sample. (b) Electrofishing operation. (c) 1, Luciobarbus ksibi (Boulenger, 1905); 2, Lepomis gibbosus (Linnaeus, 1758); 3, Carasobarbus fritschii (Günther, 1874); 4, Luciobarbus zayanensis Doadrio, Casal-lopez \& Yahyaoui, 2016; 5, Labeobarbus maroccanus (Günther, 1874); 6, Gambusia holbrooki Girard, 1859; 7, Luciobarbus magniatlantis (Pellegrin, 1919) 
holbrooki, Labeobarbus maroccanus, Lepomis gibbosus, Luciobarbus ksibi, Luciobarbus magniatlantis, and Luciobarbus zayenensis) were mixed for $5 \mathrm{~min}$ in a tray to ensure identical conditions for glochidia uptake. Then, each species was placed in separate aquaria with a net at the bottom to avoid glochidia consumption (with between three and 10 individuals of each species, and with two or three replicate aquaria per species). The water in the aquaria was syphoned daily through a sieve of $60 \mu \mathrm{m}$ to check for glochidia or juveniles. The metamorphosis of the glochidia into juveniles was evaluated under a stereoscope by observing any active foot movement. After counting, the transformation success of glochidia into juveniles was used to calculate the transformation rate (TR) for each fish species [(number of live juveniles produced/number of infested glochidia in the water)*100].

In order to determine whether there were any significant differences between the proportions of fish that were found at each site and those that were infested, a chi-square test was applied using MINITAB 14

All animal protocols and procedures were ethically reviewed and approved by the High Commission for Water and Forests (HCEFLCD).

\section{I RESULTS}

\section{1 | Fish species composition and natural infestation}

In total, 552 fish individuals belonging to three families (Cyprinidae, Centrarchidae, and Poeciliidae) were collected between January and June 2017, with 274 belonging to six species in the Laabid River and
278 belonging to five species in the N'Fis River (Figure 2). Among these three families, the species belonging to the family Cyprinidae were the most common in both rivers. The Cyprinidae in the Laabid River are represented by four species in three genera, and in the N'Fis River by three species in two genera. The non-native species from the families Centrarchidae and Poeciliidae were rarely found. The total fish density varied little within and between the two rivers throughout the study period, ranging between 0.55 (Laabid River) and 0.67 ind. $\mathrm{m}^{-2}$ (N'Fis River). In the Laabid River, the minimum density of fish occurred in February $\left(0.40\right.$ ind. $\left.\mathrm{m}^{-2}\right)$ and the maximum density of fish occurred in June ( 0.77 ind. $\mathrm{m}^{-2}$ ) (Table 1$)$. In the N'Fis River, the minimum density was recorded in April $\left(0.50\right.$ ind. $\left.\mathrm{m}^{-2}\right)$ and the maximum density was recorded in May (0.87 ind. $\mathrm{m}^{-2}$ ) (Table 1). With the exception of June, the N'Fis River always showed higher densities than the Laabid River (Table 1). During the 5 months of monitoring, C. fritschii was the most represented species in both rivers $(43.83 \%$ in the Laabid and $51.03 \%$ in the N'Fis). The other cyprinid species were moderately represented (L. zayanensis $20.84 \%$, L. maroccanus 13.75\%, and L. ksibi $15.60 \%$ in the Laabid River, and L. magniatlantis $21.76 \%$ and L. ksibi $15.69 \%$ in the N'Fis River) (Table 1). Non-native species (L. gibbosus and G. holbrooki) were less abundant, with $5.98 \%$ and $11.52 \%$ in the Laabid and the N'Fis rivers, respectively (Table 1).

The average $( \pm S D)$ abundance of $U$. foucauldianus was higher in the N'Fis River (24.00 \pm 5.66 ind. CPUE) than in the Laabid River (10.00 \pm 1.41 ind. CPUE).

In total, 677 glochidia on 164 individual fish were observed from March to June 2017. The infestations in the two rivers were different, with a greater infestation of the fish in the N'Fis River (453 glochidia) than in the fish of the Laabid River (224 glochidia). The average

TABLE 1 Fish species composition, relative abundance, and fish density (ind. $\mathrm{m}^{-2}$ ) in two Unio foucauldianus rivers

\begin{tabular}{|c|c|c|c|c|c|c|c|c|c|c|c|}
\hline & \multicolumn{2}{|l|}{ Jan } & \multicolumn{2}{|l|}{ Feb } & \multicolumn{2}{|c|}{ Mar-Apr } & \multicolumn{2}{|l|}{ May } & \multicolumn{2}{|l|}{ Jun } & \multirow{2}{*}{$\begin{array}{l}\text { Mean } \\
\text { Density }\end{array}$} \\
\hline & $D$ (ind. $\mathrm{m}^{-2}$ ) & A\% & D & A\% & D & A\% & D & A\% & D & A\% & \\
\hline \multicolumn{12}{|l|}{ Laabid River } \\
\hline Carasobarbus fritschii & 0.25 & 48.65 & 0.17 & 41.38 & 0.18 & 40.63 & 0.29 & 46.67 & 0.32 & 41.82 & \\
\hline Luciobarbus zayanensis & 0.1 & 18.92 & 0.08 & 20.69 & 0.11 & 25.00 & 0.11 & 17.78 & 0.17 & 21.82 & \\
\hline Labeobarbus maroccanus & 0.06 & 10.81 & 0.08 & 20.69 & 0.04 & 9.38 & 0.08 & 13.33 & 0.11 & 14.55 & \\
\hline Lepomis gibbosus* & 0.03 & 5.41 & 0.01 & 3.45 & 0.03 & 6.25 & 0.03 & 4.44 & 0.03 & 3.64 & \\
\hline Gambusia holbrooki* & 0.01 & 2.70 & 0.00 & 0.00 & 0.00 & 0.00 & 0.01 & 2.22 & 0.01 & 1.82 & \\
\hline Total density (Laabid River) & 0.52 & & 0.40 & & 0.44 & & 0.62 & & 0.77 & & 0.55 \\
\hline \multicolumn{12}{|l|}{ N'fis River } \\
\hline Lepomis gibbosus* & 0.05 & 6.38 & 0.08 & 13.16 & 0.03 & 6.67 & 0.08 & 9.62 & 0.03 & 6.06 & \\
\hline Gambusia holbrooki* & 0.03 & 4.26 & 0.02 & 2.63 & 0.00 & 0.00 & 0.05 & 5.77 & 0.02 & 3.03 & \\
\hline Total density (N'Fis River) & 0.79 & & 0.63 & & 0.5 & & 0.87 & & 0.55 & & 0.67 \\
\hline
\end{tabular}

$\mathrm{D}$, density; A\%, relative abundance as a percentage.

${ }^{*}$ Non native species. 
number of glochidia per fish was distinct within and among the species throughout the sampling period in the two rivers. Labeobarbus maroccanus was the most infested species in the Laabid River (4.26 \pm 3.37 glochidia per fish); the other species were less infested (with $2.44 \pm 2.10,1.84 \pm 2.17,1.18 \pm 0.69$ and $0.08 \pm 0.18$ glochidia per fish for L. zayanensis, L. ksibi, C. fritschii, and G. holbrooki, respectively). For the N'Fis River, L. magniatlantis was the most infested species (11.48 \pm 12.36 glochidia per fish), whereas L. ksibi and C. fritschil were only moderately infested (with $3.26 \pm 2.71$ and $3.04 \pm 2.49$ glochidia per fish, respectively). Lepomis gibbosus was the least infested species, with $1.00 \pm 1.73$ glochidia per fish. The peak of glochidial infestation was observed at the beginning of May for the Laabid River and at the end of May for the N'Fis River (Figure 3).

Significant differences were found between the proportion of fish sampled and the proportion of fish that were infested in both rivers $(\chi 2=77.382, P<0.001$ for the Laabid River; $\chi 2=189.67, P<0.001$ for the N'Fis River).

\subsection{Laboratory infestations}

Glochidial release began on 9 May 2017. Glochidia are triangular and hooked in a similar way to other Unio species (Figure 4), with a total length of $0.19-0.21 \mathrm{~mm}$. The time span of glochidial release ranged between 1 and 3 days for different mussel individuals. The timing of excystment and the transformation rate of $U$. foucauldianus juveniles varied among different fish host species. For C. fritschii, fully transformed juveniles of $U$. foucauldianus from the Laabid River started to appear on day 5 post-infestation (PI) and on day $6 \mathrm{PI}$ for the N'Fis River. Transformed juveniles were then recorded for the next 14 days (TR 33.0\%) for the Laabid River and 12 days (TR 28.3\%) for the N'Fis River. For L. maroccanus, juveniles were observed from day 7 to day 12 PI (TR 47.2\%) in the Laabid River. For L. zayanensis, juveniles were released from day 7 to day 12 PI (TR 62.0\%) in the Laabid River. As for L. ksibi, the infestation was successful at both sites and juveniles were observed between days 8 and 12 PI (TR 38.1\%) and between days 5 and 13 PI (TR 43.4\%) for the Laabid and the N'Fis rivers, respectively. For L. magniatlantis, juveniles were observed from day 7 to day 12 PI (TR 48.6\%) in the N'Fis River (Figure 5).

Applying the concept of degree-days (i.e. the sum of daily water temperatures), the transformation duration also varied across species and between both rivers: in the Laabid River it varied between 90 and 448 degree-days, and in the N'Fis River between 90 and 348 degree-days (Figure 5).

For L. gibbosus and G. holbrooki no fully transformed juveniles were observed despite the fact that both non-native fish species were infested with glochidia (until day 7 PI for L. gibbosus and day 5 PI for G. holbrooki).

\section{4 | DISCUSSION}

Five native cyprinid fish, four endemic to Morocco, are reported here for the first time as suitable hosts for $U$. foucauldianus. These fish species have a restricted distribution in north-west Africa: $C$. fritschii is distributed in all main Moroccan basins and certain basins in Algeria; L. ksibi occurs in the Oum Er Rbia and Tensift basins, L. magniatalantis is endemic to the Tensift basin, and L. zayanensis and L. maroccanus are endemic to the Oum Er Rbia basin (Azeroual, 2003; Casal-López, Perea, Yahyaoui, \& Doadrio, 2015; Doadrio, Casal-López, Perea, \& Yahyaoui, 2016).

Cyprinids were the most abundant fish group at both sites, with an average of $94.02 \%$ and $88.48 \%$ in the Laabid and N'Fis rivers, respectively. These percentages are higher than the average for the family Cyprinidae across Morocco, with $44 \%$ of the total fish fauna (Azeroual, 2003). Although no study has been dedicated to the fish hosts of

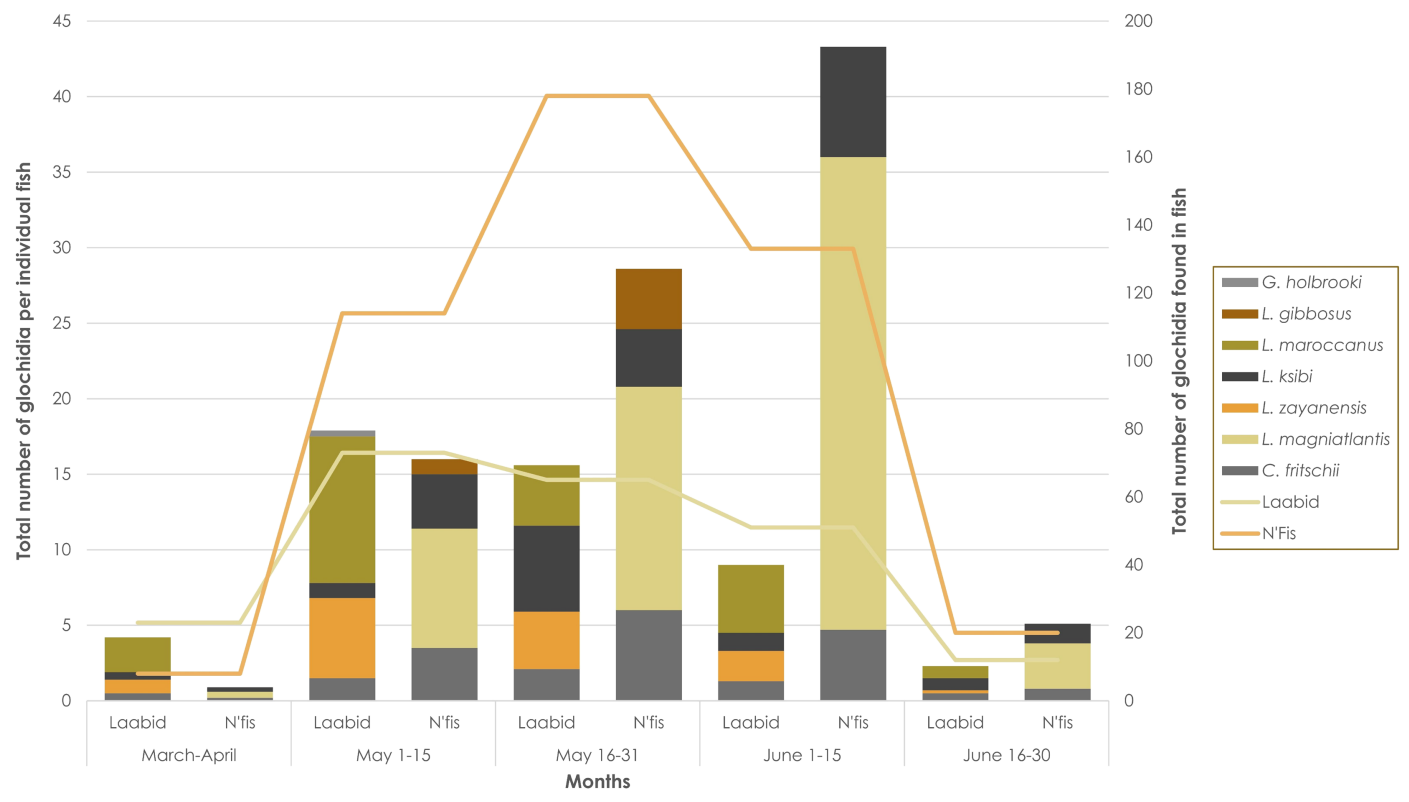

FIGURE 3 Infestation rate of glochidia per individual fish and total number of glochidia of Unio foucauldianus found in each river per month 


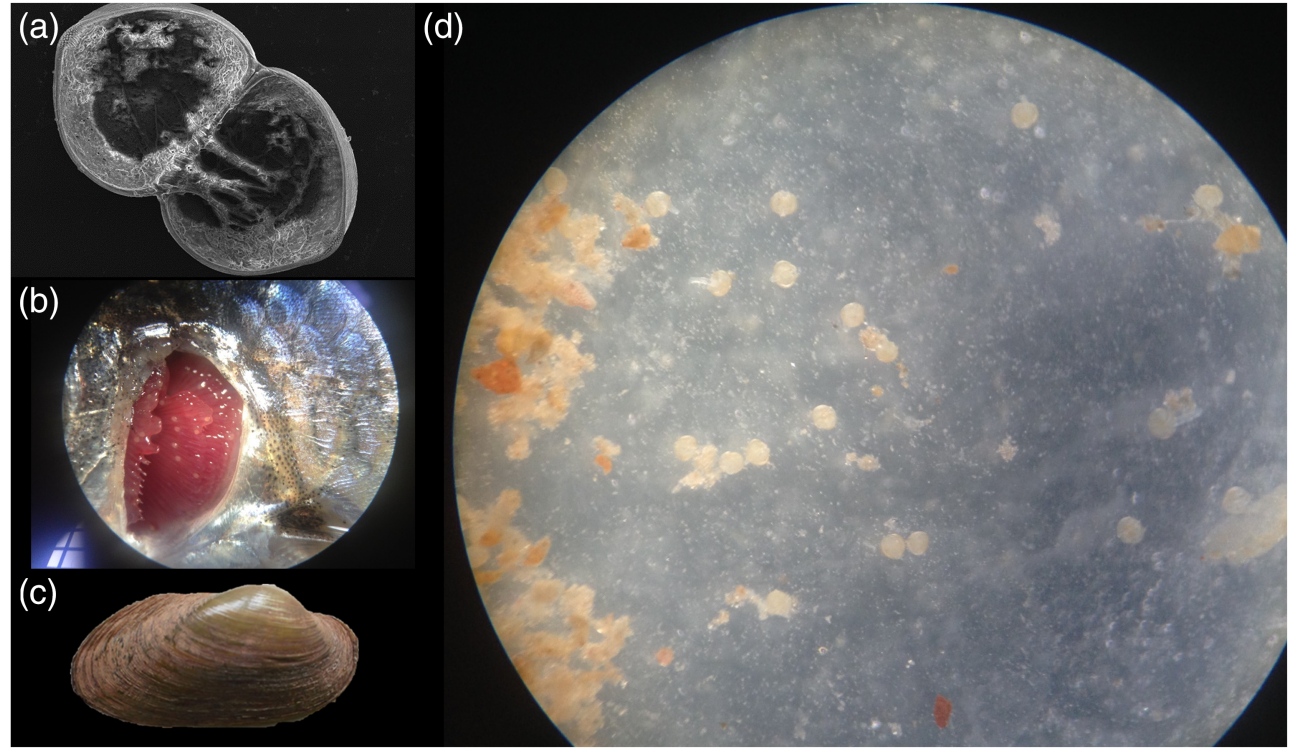

FIGURE 4 (a) Unio foucauldianus glochidia. (b) Infestation of gills by glochidia. (c) Adult of Unio foucauldianus Pallary, 1936. (d) Juvenile U. foucauldianus

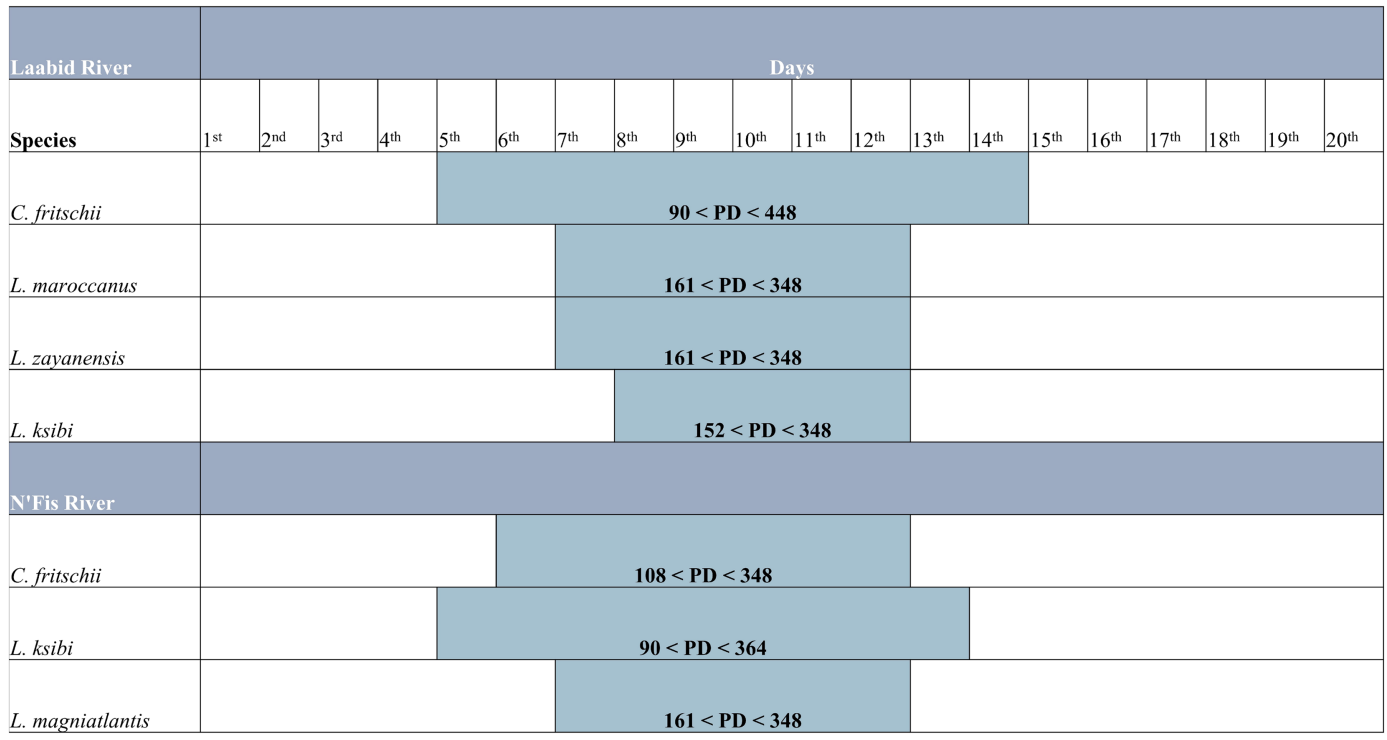

FIGURE 5 Transformation of glochidia of Unio foucauldianus into juveniles in degree-days (PD, parasitism duration)

U. foucauldianus, the association of freshwater mussel species within the Unio genus and cyprinids has been observed, with almost $75 \%$ of the fish hosts of the European Unio species belonging to this family (Lopes-Lima et al., 2017).

The fish from the N'Fis River present a much higher infestation rate than those in the Laabid River, perhaps because flow in the N'Fis River during spring and summer is intermittent, giving more opportunity for the glochidia to infest the fish, whereas the permanent flow of the Laabid River dilutes the glochidial concentration. The higher glochidial loads in the N'Fis River might also be explained by the higher abundance of $U$. foucauldianus at the study site, compared with the Laabid River. In fact, the glochidial loads are positively correlated with the density of the fish hosts, and the densities of the endemic cyprinids common to both rivers (C. fritschii and L. ksibi) are similar in both rivers.

There are highly significant differences between the proportion of fish in the community and those infested, indicating a preference of $U$. foucauldianus for specific fish hosts. Glochidial loads under natural infestation differ in both rivers, however: L. maroccanus and L. zayanensis seem to be the most favourable hosts for $U$. foucauldianus in the Laabid River, compared with L. magniatlantis, C. fritschii, and L. ksibi in the N'Fis River, whereas L. ksibi and C. fritschii are the least favourable native hosts in the Laabid River.

The results of the transformation rate of glochidia into juveniles showed that only L. zayanensis has a TR > 50\%; the other species (C. fritschii, L. maroccanus, and L. magniatlantis) have a lower 
transformation rate, suggesting that $L$. zayanensis is the primary host species for $U$. foucauldianus.

Carasobarbus fritschii and L. ksibi, the two species that occur in both rivers, have similar rates of metamorphosis in each river. This result is indicative of a weak population-level difference in physiological compatibility, in contrast to the detected differences in natural glochidial loads across species. This finding is contrary to what was been recognized previously (Douda et al., 2014) and could suggest that both $U$. foucauldianus populations are closely related, which does not seem to be the case as these populations are from distinct river basins.

The non-native species (L. gibbosus and G. holbrooki) are not suitable hosts for $U$. foucauldianus. In spite of the fact that these species were found to be naturally infested in the fins and gills, no juveniles have been detected during any of the artificial infestation trials, and this is probably because of an immune response with antibody production against glochidial tissue (Meyers, Millemann, \& Fustish, 1980; O'Connell \& Neves, 1999), resulting from the lack of co-evolution between $U$. foucauldianus and these non-native fish. The incompatibility of $U$. foucauldianus with the two non-native fish species is an additional threat posed to these mussels, as already described for other species (Douda et al., 2013; Moore et al., 2019). Non-native fish represent a direct threat to native fish and therefore to $U$. foucauldianus, because any glochidia infesting these non-native fish will be lost. Although the density of these two species was very low in both rivers, several nonnative fish species are being actively introduced in most of Morocco's dams, such as Bin El Ouidane Dam (Laabid River) and Lalla Takerkoust Dam (N'Fis River), for biological insect control (mosquitofish) or as prey for predator fish species (pumpkinseed) (Mouslih, 1987). Both species might become established and expand their distribution, thereby imposing an additional threat to native fish communities and ecosystems (for a review of the impact of eastern mosquitofish and pumpkinseed, see Macdonald \& Tonkin, 2008 and Van Kleef, Van Der Velde, Leuven, \& Esselink, 2008).

The excystment period of $U$. foucauldianus varied across the different host species, and the timing also varied between 90 and 448 degree-days for the average temperature of $23^{\circ} \mathrm{C}$. The range is wider than that described for other Unio species such as Unio crassus that has a developmental time of between 265 and 357 degree-days (Taeubert, El-Nobi, \& Geist, 2014). These differences may arise from the type of host species infested or the high temperatures found in Moroccan rivers. In addition, because the daily variation in water temperature is high in Morocco, and as temperature plays a major role in the development and growth of poikilothermic animals such as invertebrates (Bauer, 1992; Manoj Nair \& Appukuttan, 2003), the wider variation in the development time reported here may be a response to this situation. Further studies are necessary to test this hypothesis, however.

\section{5 | CONCLUSIONS}

This study presents the first results on the freshwater mussel-fish host relationship of the endemic and Critically Endangered
U. foucauldianus (Van Damme \& Ghamizi, 2010). The freshwater mussel-fish relationship makes the conservation of unionids difficult. Unio foucauldianus has suffered a dramatic decline in distribution and abundance in recent years, owing to climate change, habitat loss, fragmentation, water pollution, and overexploitation (Gomes-dosSantos et al., 2019; Van Damme, Ghamizi, Soliman, \& Mclvor, 2010). The present study adds to this list the introduction of nonnative fish species as a possible important threat. Given this situation (i.e. the substitution of native fish species with non-native fish species), future conservation measures for $U$. foucauldianus should include the maintenance of ecological flows adequate for this species and the effective management of water abstraction activities at the permanent sections of rivers that act as a refuge for this species and their hosts during the dry season. In addition, the monitoring and management of non-native fish species are extremely important in order to design control-and-containment strategies, or even eradication programmes. Unio foucauldianus will also profit from improvements in the wastewater treatment network in order to reduce urban pollution, mainly in the most densely human populated areas. As $U$. foucauldianus is not legally protected, it would also benefit from a conservation action plan to persuade the national environmental authorities to implement policies for protecting and conserving this and other freshwater mussel species. This approach might include adapting the protected area network to include freshwater habitats, monitoring ecological flows and groundwater abstraction activities, and the promotion of captive breeding programmes. Physiological compatibility seems to be rather stable across sites, so any eventual propagation programmes would benefit from using the most suitable host fish, L. zayanensis, for the ex situ captive breeding of $U$. foucauldianus. The conservation measures proposed here can be further extrapolated to most unionoid species in Morocco, and to other areas in one of the most diverse regions of the world, also known as the Mediterranean biodiversity hotspot (Myers et al., 2000), that share most of the same environmental problems.

\section{ACKNOWLEDGEMENTS}

The authors would like to express their thanks to the High Commission for Water and Forests (HCEFLCD) for granting permission to use electrofishing in the Moroccan basins. This study was conducted within the scope of the project 'Biodiversity and conservation of the critically endangered freshwater mussels in Morocco: ecogeographic, genetic and physiological information', funded by the Mohamed Bin Zayed Species Conservation Fund (ref. 15256799), and the project 'Breeding the most endangered bivalve on Earth: Margaritifera marocana', funded by the IUCN SOS (Save our Species) fund (ref. 2015B-015).

\section{ORCID}

Hassan Benaissa (iD https://orcid.org/0000-0002-0450-5220

Manuel Lopes-Lima (D) https://orcid.org/0000-0002-2761-7962

Ronaldo Sousa (D) https://orcid.org/0000-0002-5961-5515 


\section{REFERENCES}

Agence du bassin hydraulique de I'Oum Er Rabia (ABHOER). (2017). Rapport Sur la situation hydrologique du bassin d'Oum Er Rabia. Maroc.

Agence japonaise de coopération internationale (JICA). (2007). Etude du plan de gestion intégrée des ressources en eau dans la Plaine du Haouz royaume du Maroc, 138. Maroc.

Amaya, A., Algouti, A., \& Algouti, A. (2014). The use of remote sensing and GIS to identify water erosion risks areas in the Moroccan High Atlas. The case study of the N'Fis wadi watershed. International Journal of Sciences, 02, 43-51.

Arey, L. B. (1921). An experimental study on glochidia and the factors underlying encapsulation. Journal of Experimental Zoology, 33, 463-499. https://doi.org/10.1002/jez.1400330209

Azeroual, A. (2003). Monographie des poissons des eaux continentales du Maroc: Systématique, distribution et écologie ( $\mathrm{PhD}$ thesis). Université Mohammed V-Agdal, Rabat, Morocco.

Bauer, G. (1992). Variation in the life span and size of the freshwater pearl mussel. Journal of Animal Ecology, 61, 425-436. https://doi.org/ $10.2307 / 5333$

Casal-López, M., Perea, S., Yahyaoui, A., \& Doadrio, I. (2015). Taxonomic review of the genus Luciobarbus Heckel, 1843 (Actinopterygii, Cyprinidae) from Northwestern Morocco with the description of three new species. Graellsia, 71: e027.

Ćmiel, A. M., Zając, K., Lipińska, A. M., \& Zając, T. (2018). Glochidial infestation of fish by the endangered thick-shelled river mussel Unio crassus. Aquatic Conservation: Marine and Freshwater Ecosystems, 28, 535-544. https://doi.org/10.1002/aqc.2883

Coker, R. E., Shira, A. F., Clark, H. W., \& Howard, A. D. (1921). Natural history and propagation of fresh-water mussels. Document No. 893. Bulletin of the Bureau of Fisheries, 37, 77-181.

Denic, M., Taeubert, J. E., \& Geist, J. (2015). Trophic relationships between the larvae of two freshwater mussels and their fish hosts. Invertebrate Biology, 134, 129-135. https://doi.org/10.1111/ivb.12080

Doadrio, I., Casal-López, M., Perea, S., \& Yahyaoui, A. (2016). Taxonomy of rheophilic Luciobarbus Heckel, 1842 (Actinopterygii, Cyprinidae) from Morocco with the description of two new species. Graellsia, 72, e039. https://doi.org/10.3989/graellsia.2016.v72.153

Douda, K., Horký, P., \& Bílý, M. (2012). Host limitation of the thick-shelled river mussel: Identifying the threats to declining affiliate species. Animal Conservation, 15, 536-544. https://doi.org/10.1111/j.14691795.2012.00546.x

Douda, K., Lopes-Lima, M., Hinzmann, M., Machado, J., Varandas, S., Teixeira, A., \& Sousa, R. (2013). Biotic homogenization as a threat to native affiliate species: Fish introductions dilute freshwater mussel's host resources. Diversity and Distributions, 19, 933-942. https://doi. org/10.1111/ddi.12044

Douda, K., Sell, J., Kubíková-Peláková, L., Horký, P., Kaczmarczyk, A., \& Mioduchowska, M. (2014). Host compatibility as a critical factor in management unit recognition: Population-level differences in musselfish relationships. Journal of Applied Ecology, 51, 1085-1095. https:// doi.org/10.1111/1365-2664.12264

Fritts, M. W., Fritts, A. K., Carleton, S. A., \& Bringolf, R. B. (2013). Shifts in stable-isotope signatures confirm parasitic relationship of freshwater mussel glochidia attached to host fish. Journal of Molluscan Studies, 79, 163-167. https://doi.org/10.1093/mollus/eyt008

Froufe, E., Goncalves, D. V., Teixeira, A., Sousa, R., Varandas, S., Ghamizi, M., ... Lopes-Lima, M. (2016). Who lives where? Molecular and morphometric analyses clarify which Unio species (Unionida, Mollusca) inhabit the southwestern Palearctic region. Organisms Diversity \& Evolution, 16, 597-611. https://doi.org/10.1007/s13127-016-0262-x
Gomes-dos-Santos, A., Froufe, E., Gonçalves, D. V., Sousa, R., Prié, V., Ghamizi, M., ... Lopes-Lima, M. (2019). Freshwater conservation assessments in (semi-)arid regions: Testing river intermittence and buffer strategies using freshwater mussels (Bivalvia, Unionida) in Morocco. Biological Conservation, 236, 420-434. https://doi.org/ 10.1016/j.biocon.2019.05.038

Haag, W. R. (2012). North American freshwater mussels: Natural history, ecology, and conservation. Cambridge: Cambridge University Press. https://doi.org/10.1017/СBO9781139048217

Lamand, F., Roche, K., \& Beisel, J. N. (2016). Glochidial infestation by the endangered mollusc Unio crassus in rivers of north-eastern France: Phoxinus phoxinus and Cottus gobio as primary fish hosts. Aquatic Conservation: Marine and Freshwater Ecosystems, 26, 445-455. https:// doi.org/10.1002/aqc.2603

Lopes-Lima, M., Burlakova, L. E., Karatayev, A. Y., Mehler, K., Seddon, M., \& Sousa, R. (2018). Conservation of freshwater bivalves at the global scale: Diversity, threats and research needs. Hydrobiologia, 810, 1-14. https://doi.org/10.1007/s10750-017-3486-7

Lopes-Lima, M., Sousa, R., Geist, J., Aldridge, D. C., Araujo, R., Bergengren, J., ... Zogaris, S. (2017). Conservation status of freshwater mussels in Europe: State of the art and future challenges. Biological Reviews, 92, 572-607. https://doi.org/10.1111/brv.12244

Lopes-Lima, M., Teixeira, A., Froufe, E., Lopes, A., Varandas, S., \& Sousa, R. (2014). Biology and conservation of freshwater bivalves: Past, present and future perspectives. Hydrobiologia, 735, 1-13. https://doi.org/ 10.1007/s10750-014-1902-9

Macdonald, J., \& Tonkin, Z. (2008). A review of the impact of eastern gambusia on native fishes of the Murray-Darling Basin. Murray-Darling Basin Authority Publication No. 38/09. Canberra.

Manoj Nair, R., \& Appukuttan, K. K. (2003). Effect of temperature on the development, growth, survival and settlement of green mussel Perna viridis (Linnaeus, 1758). Aquaculture Research, 34, 1037-1045. https://doi.org/10.1046/j.1365-2109.2003.00906.x

Meyers, T., Millemann, R., \& Fustish, C. (1980). Glochidiosis of salmonid fishes. IV. Humoral and tissue responses of coho and chinook salmon to experimental infection with Margaritifera margaritifera (L.) (Pelecypoda: Margaritanidae). The Journal of Parasitology, 66, 274-281. https://doi.org/10.2307/3280818

Modesto, V., Ilarri, M., Souza, A. T., Lopes-Lima, M., Douda, K., Clavero, M., \& Sousa, R. (2018). Fish and mussels: Importance of fish for freshwater mussel conservation. Fish and Fisheries, 19, 244-259. https://doi.org/ 10.1111/faf.12252

Moore, T. P., Collier, K. J., \& Duggan, I. C. (2019). Interactions between Unionida and non-native species: A global meta-analysis. Aquatic Conservation: Marine and Freshwater Ecosystems, 29, 1438-1451.

Mouslih, M. (1987). Introduction de poissons et d'écrevisses au Maroc, Revue d'Hydrobiologie Tropicale, 20, 73-84.

Nagel, K. O., \& Castagnolo, L. (1991). Fish hosts for the glochidium of Unio mancus. Rivista di Idrobiologia, 30, 339-346.

O'Connell, M. T., \& Neves, R. J. (1999). Evidence of immunological response by a host fish (Ambloplites rupestris) and two non-host fishes (Cyprinus carpio and Carasius auratus) to glochidia larvae. Journal of Freshwater Ecology, 14, 71-78. https://doi.org/10.1080/ 02705060.1999 .9663656

Reis, J., Collares-Pereira, M. J., \& Araujo, R. (2014). Host specificity and metamorphosis of the glochidium of the freshwater mussel Unio tumidiformis (Bivalvia: Unionidae). Folia Parasitologica, 61, 81-89. https://doi.org/10.14411/fp.2014.005

Schneider, L. D., Nilsson, A., Höjesjö, J., \& Österling, M. (2017). Local adaptation studies and conservation: Parasite-host interactions between the endangered freshwater mussel Unio crassus and its host fish. 
Aquatic Conservation: Marine and Freshwater Ecosystems, 27, 1261-1269. https://doi.org/10.1002/aqc.2816

Sousa, R., Teixeira, A., Santos, A., Benaissa, H., Varandas, S., Ghamizi, M., ... Lopes-Lima, M. (2018). Oued Bouhlou: A new hope for the Moroccan pearl mussel. Aquatic Conservation: Marine and Freshwater Ecosystems, 28, 247-251. https://doi.org/10.1002/aqc.2825

Sousa, R., Varandas, S., Teixeira, A., Ghamizi, M., Froufe, E., \& Lopes-Lima, M. (2016). Pearl mussels (Margaritifera marocana) in Morocco: Conservation status of the rarest bivalve in African fresh waters. Science of the Total Environment, 547, 405-412. https://doi.org/10.1016/j. scitotenv.2016.01.003

Taeubert, J. E., El-Nobi, G., \& Geist, J. (2014). Effects of water temperature on the larval parasitic stage of the thick-shelled river mussel (Unio crassus). Aquatic Conservation: Marine and Freshwater Ecosystems, 24, 231-237. https://doi.org/10.1002/aqc.2385

Taeubert, J. E., Gum, B., \& Geist, J. (2012). Host-specificity of the endangered thick-shelled river mussel (Unio crassus, Philipsson 1788) and implications for conservation. Aquatic Conservation: Marine and Freshwater Ecosystems, 22, 36-46. https://doi.org/10.1002/aqc.1245

Taeubert, J. E., Martinez, A. M. P., Gum, B., \& Geist, J. (2012). The relationship between endangered thick-shelled river mussel (Unio crassus) and its host fishes. Biological Conservation, 155, 94-103. https://doi.org/ 10.1016/j.biocon.2012.06.005

Van Damme, D., \& Ghamizi, M. (2010). Unio foucauldianus. The IUCN Red List of Threatened Species 2010: E.T184708A8318610. http://dx.doi.
or/10.2305/IUCN.UK.2010-3.RLTS.T184708A8318610.en. Downloaded on 24 July 2017.

Van Damme, D., Ghamizi, M., Soliman, G., Mclvor, A., \& Seddon, M. B. (2010). The status and distribution of freshwater molluscs. In N. Garcia, A. Cuttelod, \& D. Abdul Malak (Eds.), The status and distribution of freshwater biodiversity in northern Africa (pp. 29-50). Gland, Switzerland, Cambridge, UK, and Malaga, Spain: IUCN.

Van Kleef, H., Van Der Velde, G., Leuven, R. S. E. W., \& Esselink, H. (2008). Pumpkinseed sunfish (Lepomis gibbosus) invasions facilitated by introductions and nature management strongly reduce macroinvertebrate abundance in isolated water bodies. Biological Invasions, 10, 1481-1490. https://doi.org/10.1007/s10530-008-9220-7

Watters, G. T. (2001). The evolution of the Unionacea in North America, and its implications for the worldwide fauna. In G. Bauer \& K. Wachtler (Eds.), Ecology and evolution of the freshwater mussels Unionoida, Ecological Studies (Vol. 145, pp. 281-307). Berlin, Germany: Springer.

How to cite this article: Benaissa $\mathrm{H}$, Teixeira $\mathrm{A}$, Lopes-Lima $\mathrm{M}$, et al. Fish hosts of the freshwater mussel Unio foucauldianus Pallary, 1936. Aquatic Conserv: Mar Freshw Ecosyst. 2019;29: 2176-2184. https://doi.org/10.1002/aqc.3234 